Article

\title{
Application of the DEMATEL Model for Assessing IT Sector's Sustainability
}

\author{
Kęstutis Peleckis
}

\section{check for}

updates

Citation: Peleckis, K. Application of the DEMATEL Model for Assessing IT Sector's Sustainability. Sustainability 2021, 13, 13866. https://doi.org/ $10.3390 /$ su132413866

Academic Editor: Barbara Motyl

Received: 18 November 2021 Accepted: 10 December 2021 Published: 15 December 2021

Publisher's Note: MDPI stays neutral with regard to jurisdictional claims in published maps and institutional affiliations.

Copyright: (C) 2021 by the author. Licensee MDPI, Basel, Switzerland. This article is an open access article distributed under the terms and conditions of the Creative Commons Attribution (CC BY) license (https:// creativecommons.org/licenses/by/ $4.0 /)$.
Department of Economics Engineering, Faculty of Business Management, Vilnius Gediminas Technical University, LT-10223 Vilnius, Lithuania; k.peleckis@vilniustech.lt

\begin{abstract}
Understanding what are the IT sector's business opportunities under distorted market conditions is a growing interest in sustainability research. This article investigates how to assess the IT sectors sustainability through a multicriterion assessment. For the assessment of the IT sector's European and Slovenian competition policy, the DEMATEL technique was chosen. Fifteen economical performance indicators of IT sectors companies in 2015-2019 were selected for analysis. Given the multiplicity of criteria addressed in the sustainability issues, a multi-criteria analysis was used with the assistance of experts. In this research, the DEMATEL technique was developed for problem solving, for the assessment of the concentration of business entities that affect the competitive situation of economy. Results showed that comparison of the DEMATEL method with fuzzy and probability theories proved that it is possible to measure IT sector's HHI-based performance.
\end{abstract}

Keywords: DEMATEL method; sustainability; IT sector; fuzzy method; distorted competition

\section{Introduction}

Recent researches have shown that market distortions are devastating [1-5]. When the economy is undeveloped, the economic system is not mature; therefore, under conditions of imperfect market mechanism and strong international competitive pressure for governments, there is often a need to make big policy distortions in an attempt to mobilize economic resources for the developement of the domestic industry and its competitive advantage. When an economy enters in a higher stage of development with a more mature system and market mechanism, excessive policy distortions are not conducive to the efficient allocation of economic resources. The market of the IT sector can increase the efficiency of innovations and sustainable growth of profits, especially when firms change their behavior in regards to incentives. With the rapid development of the economy, the phenomena of capital market distortion and labor market distortion are a matter of concern [6-14]. Therefore, in this article, we will try to apply the DEMATEL model for the sustainability assessment of the IT sector.

The DEMATEL method is commonly used in order to obtain a cause-and-effect scheme among the dependent factors. This method is superior to conventional methods as it discloses interfaces among the criteria. The criteria are ranked depending on the type of the relationship and reveal the intensity of their effects for each other. While one method is not sufficient to identify occupational risks in the presence of uncertainty and ambiguity, an integrated approach is needed to solve the problem under consideration. Therefore, fuzzy linguistic modeling is used to represent and process flexible information. The suitability of this method for assessing the IT sector's sustainability is manifested through the possibility to arrange the criteria and assess the intensity of exposure for each other. Accordingly, the DEMATEL method is used to determine impact and cause of criteria and increase the adaptability of the model with respect to linguistic variables along with triangular fuzzy numbers. Using a multi-criteria decision-making approach, DEMATEL contributes to the risk assessment literature by presenting a different approach for providing an assessment that enables the modeling of the cause and effect of risk factors 
and the analytical disclosure of the degree or strength of influence. In the article, we present information about advantages of the DEMATEL method for the IT sector's sustainability assessment, a comparison of the DEMATEL method with fuzzy and probability theories, the modified DEMATEL technique for problem solving, as well as the steps involved in the DEMATEL method algorithm. These results are significant for academics as the basis for further research, and for decision-makers as a guidance for the development of the evaluation of business concentration that affects the competitive situation in economic aspects. In the face of today's distorted market challenges, there is a lack of effective tools for properly assessing the sustainability of the IT sector.

To solve the problem of the research, the following tasks have been set:

(1) To evaluate the advantages of the DEMATEL method for the risk assessment.

(2) To carry out the comparison of the DEMATEL method with fuzzy and probability theories.

(3) To perform the comparison of the DEMATEL method with fuzzy and probability theories.

(4) To assess the concentration of IT sector's business entities that affect the competitive economic situation.

(5) To verify empiricaly the implementation of the multi-criteria evaluation model for the IT sector's sustainability.

\section{Literature Review}

\subsection{Evaluation Advantages of DEMATEL Method for the Risk Assessment}

The proposed method offers the following advantages over traditional ORA methods: the proposed method illustrates critical occupational hazards, interconnections, and constructing a causal relationship between IT sectors activities. Identification of each hazard using triangular fuzzy numbers gives better and more reliable results due to the uncertainty and ambiguity of the data, and can be controlled using the fuzzy method. The proposed approach provides a very accurate and effective material to support the risk assessment procedure, as occupational hazards can be better assessed to prevent critical hazards in the IT industry [1-6,15-21].

As a multi-criteria decision-making method, DEMATEL contributes to the risk assessment literature from different perspectives by providing an assessment that allows modeling of cause-and-effect relationships and analytically demonstrating the degree or strength of relationships. The decision-making process and evaluation laboratory method (DEMATEL) can be adapted to solve complex problems [21,22]. It works mainly by gathering opinions of experts, monitoring the degree of influence between elements, using matrix operations to obtain a causal relationship between elements, and identifying similar network schemes for modeling structural equations. The basic DEMATEL method consists of four calculation steps [22]: (1) defining the scale, (2) creating a direct connection matrix, (3) calculating a normalized matrix, and (4) calculating the matrix of direct/indirect relationships. Determination of the limit value is usually affected by the complexity of the problem and different experts' opinions. DEMATEL can help to find the main problem and improve complex systems through the degrees of interrelationship among the quantified quality characteristics. However, the DEMATEL threshold is often determined by experts according to their own decisions. If reasonably thresholds will not be established, they will affect the causal relationships between the variables [18]. To discover critical features of a complex problem, the limit value must be sufficient for further analysis. Laboratory Method for Decision Making Testing and Evaluation multi-criteria decision making has been very widely used in many management studies (e.g., operations management) to identify causal relationships between factors and to point out valuable insight in decision making.

The scope of this system has reached IT, manufacturing, social activities, farming, the financial system, environmental science, energy, and other areas and has solved many practical problems [18-20,22-26]. However, the results were found to be misleading when applied globally (or universally) or even to elements / categories of unequal weight. In this study, an example was shown in order to demonstrate serious differences in results, due to erroneous decisions. The results of the Decision-Making Testing and Evaluation Laboratory 
Method from the global calculation can be corrected if the calculations and analysis are performed based on individual elements (from a group perspective). Assessment of success or failure factors according to the individual elements of the system and their integration according to criticism set at the element level is an additional methodology to the available knowledge from the Decision-Making Testing and Evaluation Laboratory. Another new approach has been applied together with an example from a previous study. This new approach will help to find critical factors in a truly holistic way and is more reliable to implement all the principles, policy or system. Researchers studying social science topics are mostly dependent on statistics as the main analytical tool and seek to summarize sample data collected from the population. Basic assumptions of the statistical approach, such as the implied expected distribution of data sets and independence of variables, are unrealistic and inappropriate for certain real-world problems, related to complex and interrelated variables, attributes, and criteria $[25,27,28]$.

\subsection{Comparison of DEMATEL Method with Fuzzy and Probability Theories}

The Multi-Criteria Decision Making (MCDM) study seeks to solve a pre-determined problem, thus focusing more on constructing models that may be close to the decision maker's (DM) priorities and is a valuable or satisfactory guideline in decision making. In statistical methods and models, for example, in regressions, the effect of random errors is determined assuming that it is generated independently from the normal distribution with zero on average and specific variation. Although the effect of random errors assumption of probabilistic distribution is neither identified nor studied, this has some effect on the resulting regression model [29]. Therefore, as a study of ranking the success factors that enable things or barriers, based on expert judgment, the MCDM is better than tools and models of statistical analysis. According to Hwang and Yoon [17], MCDM problems can be divided into two subgroups: "Multi-Alternative Decision-Making" (MADM) and "Multi-Objective Decision-Making" (MODM). The MADM involves ranking or selection by weighing pre-determined alternatives, while the MODM aims to determine the most favorable outcome in the search for a competent boundary, decision space within the given constraints. Most routine MCDM studies include these two subgroups of the MADM and MODM [30]. The MADM methods are mainly for evaluations. In contrast, the MODM is more suitable for design or planning by optimizing the allocation of limited resources.

In discussing on multi-criteria problems, Sivakumar et al. [31] argued that the interaction criteria are basically of two categories, namely "criteria of dependency" and "criteria of interactivity". Again, the dependency criteria are divided into three types, namely, "structural dependence", "causal dependence", and "preferential dependence". Causal dependence identifies cause-and-effect relationships between factors and summarizes statistical results [31].

The DEMATEL method is used to establish complex relationships and to establish IRM relationships between criteria. The methodology can confirm the interdependence of variables / criteria and limit the relationships that reflect characteristics within essential systemic and evolving trends. However, the problem with DEMATEL may arise when some categorical system element factors, such as lean manufacturing, sustainable supply chain, and so on, do not appear to be influencing other factors, thus these less influential factors are omitted as non-critical. In order for the system to function properly or even be effectively implemented, all elements must be properly incorporated in their places. In particular, if the element is a separate integral part of the system, it must be ensured that it would be. Thus, the factors associated with that element need to be critically compared in pairs. Otherwise, the system is not fully resolved and may later fail. Generally, the influence of relationships of some factors may not be in a higher range in the overall implementation, but they may have a significant influence on a particular element of a particular principle. Therefore, distinguish factors according to the elements of the management system are analyzed and the critical factors are identified for all elements separately and then composed critically at the element level, and this needs to be supplemented with existing knowledge of the 
DEMATEL methodology. DEMATEL is sensitive to data uncertainty. If there is used of "Combined gray DEMATEL", such uncertainty is overcome. However, to accept correct solutions, DEMATEL analysis must be used for individual components or groups of elements of any system for all critical factors to occur and they would be connected to avoid any factors lost in the overall competition. Some factors may not be higher than the overall implementation, but they can have a significant impact on a particular unit of an individual element. Results can vary by a large amount when a higher number of any data (factors and elements) is used. In this case, the right weight of the elements can reduce the variability of the results, but the elementary approach remains the only right path. The concept of the DEMATEL technique derives from the well-known Leontief input-output model, which has been widely used in economics. The main advantage of the DEMATEL technique is that it can form a structural model of systemic problems to examine the strength of binary relationships (pairwise comparison) between incoming ones. The DEMATEL technical convergence problem can be considered as violation of Hawkins-Simon conditions or strictly diagonally dominant matrices.

\subsection{Developing the Modified DEMATEL Technique for IT Sectors Sustainability Assessment}

In this situation, the DEMATEL technique cannot reach a convergent solution for assessing IT sector's sustainability, thus we developed a modified DEMATEL technique to solve this problem here. On the other hand, the conventional DEMATEL technique uses only the sums of the rows and columns of the whole ratio matrix to provide decision makers with information on the relative importance of the inputs. The system and design methodology, given the specific characteristics of objective matters, can validate records and limit relationships that reflect a characteristic with a major trend. Using the DEMATEL method for the individual subjective perception to evaluate and process, it is possible to gain brief and impressionistic human insights into the complexity of the problem.

DEMATEL processes the result of the analysis as visual representation, an individual map of the mind by which one can organize one's actions in the world if internal coherence is to be maintained in order to respect implicit priorities and achieve its secret goals.

DEMATEL outline can be explained as follows. DEMATEL was established in 1972-1979 at the Geneva Battelle Memorial Institute of Science and People in the trade fair program [32]. The purpose of DEMATEL is to convert causal relationships between elements of a complex system into an understandable structural model [19]. DEMATEL helps to draw a structure of complex causal relationships between evaluation criteria using matrices or graphs. This method includes two groups-causal and consequential. The causal group influences the exposure group; therefore, the criteria weights are set. This technique allows decision makers to understand better structural relationships of system elements [33,34].

This method is used to analyze and describe the cause-and-effect relationship between the assessment criteria or by revealing the interrelationship of the factors. DEMATEL analyzes the structure of the components of each criterion, as well as the intensity of direct and indirect relationships between defined components, causal links, and strength of influence. Structural matrices and causal diagrams are used to present the causal relationship and exposure levels between criteria in a complex system.

The steps of DEMATEL (Figure 1):

(1) To gather experts' opinion and calculate the average matrix $Z$.

(2) To calculate the normalized initial direct relation matrix D.

(3) To derive the total relation matrix $T$.

(4) To calculate the sums of rows and columns of matrix T.

(5) To set the threshold value $\alpha$.

(6) To build a cause-and-effect relationship diagram.

(7) To assess if the cause-and-effect diagram is acceptable.

(8) The final cause-and effect relations. 


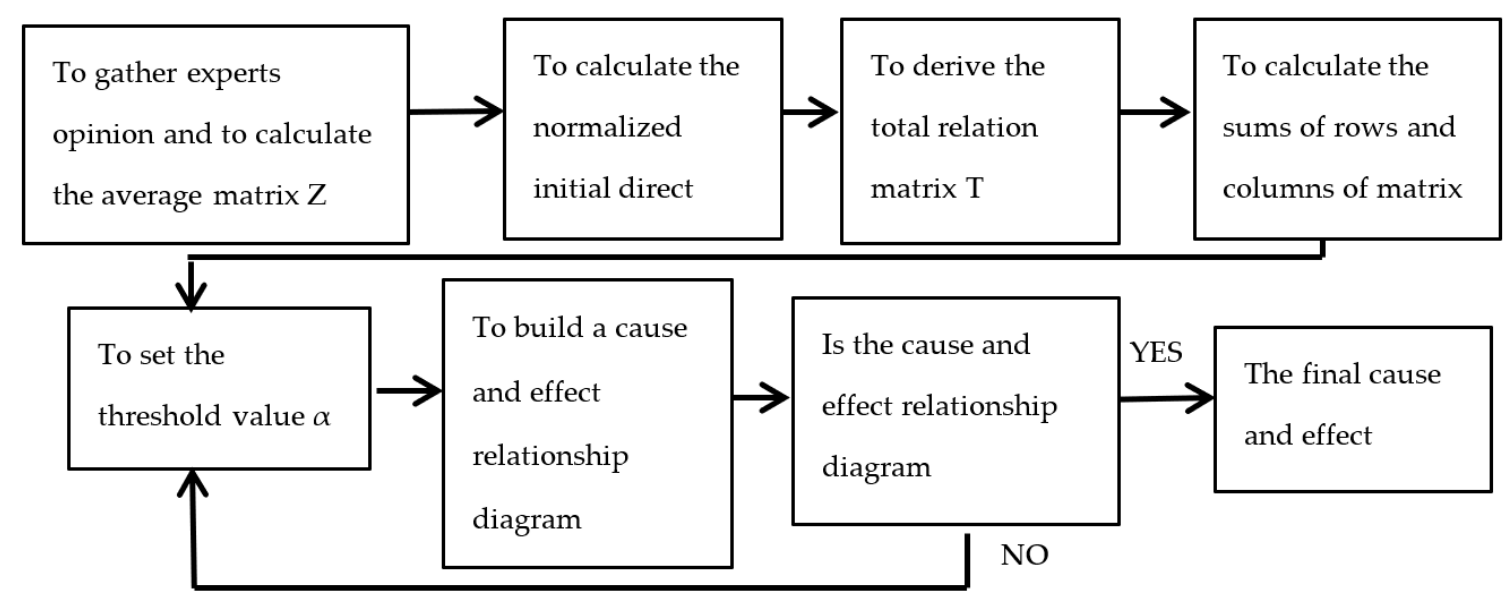

Figure 1. DEMATEL method algorithm steps.

This method confirms the relationships between variables and elements and helps to show their relationships by creating redirected schedule. Therefore, it allows us to plan and solve problems theatrically and visually. An important feature of this technique is its use in the field of multicriteria decision making, which structures the interaction of variables and elements. When the DEMATEL method is used as part of combined decision-making models, its results can influence final decisions. DEMATEL is basically based on graph theory and is very effective in evaluating and formulating all intertwined causes and exposure relationships in any structural model.

This technique is used all over the world, but it is very popular in Japan. Random connections among the factors involved can be determined by the cause-and-effect group using DEMATEL. It is possible to visualize the causal relationship of subfactors or small control relationships between individuals. The interdependence of factors/features can be assessed and the relationship between factors/features of a direct graph can be reflected using this methodology. DEMATEL helps to understand better practical solutions, a specific problem and, most importantly, a group of complex problems. The result of the DEMATEL procedure is the Impact Relationship Map (IMR) in the DEMATEL group affected of other symptoms of the cause group. This methodology helps managers to achieve structure, each factor/sub-factor which may be derived from other higher or lower-level factors.

One example of this technique is the application of feedback rather than other decisionmaking methods. In the DEMATAL study, it is possible to apply the MCDM method, to solve complex issues, evaluate, compare, and improve the effectiveness of each factor by dividing all factors into a cause-and-effect group. Using this technique, interdependencies between unpredictable aspects can be visualized using an interrelationship map (IRM). The exposure group can be easily improved by refining the cause group, because the effect is larger, according to the criteria of the exposure group. Approximate sets Zadeh were introduced in the 1960s and have been widely applied in the decision-making process under uncertain conditions for many years. Respectively, to evaluate criteria, dimensions, and alternatives, preference is given to triangular fuzzy numbers, which are commonly used in multi-criteria decisions.

\subsection{Assessing the Concentration of IT Sector's Business Entities That Affect the Competitive Situation in Economic}

Researchers have broken down the stages in assessing European and Slovenian competition policy in the IT sector [35]. The first step in the analysis was a fuzzy decisionmaking testing and evaluation laboratory (DEMATEL) technique to understand the effectrelationship map between dimensions. Using this way, the European IT sector was studied to disclose competition and concentration in the global market, thus the comparative results are discussed in order to assess the competitive policy of the European and Slovenian IT sector on integrated valuation methods in a fuzzy environment. 
Researchers are also assigned to define a decision-making problem and to establish dimensions and criteria based on the relevant literature. Thus, using an integrated fuzzy decision-making approach, it is possible to measure HHI-based performance of the European IT sector according to the proposed dimensions and criteria. The researchers sought to investigate the competition and market concentration in the European IT sector. The study selected the first three countries in terms of gross domestic product (GDP) in Europe and Turkey as alternatives. The authors obtained the data from official websites and annual reports and properly analyzed each market in the European sector. The HHI is one of measures of market diversification as a benchmark of industrial portfolio composition.

Perfect diversification is an equal reflection of each sector taking into account the systemic risk of each sector [36]. Competition and concentration levels in the European and Slovenian IT sectors were analyzed using a hybrid fuzzy decision-making approach. Competitive conditions in Germany, England, France, and Turkey were examined, and comparative results were presented to discuss competition opportunities in Europe and Turkey. Finally, the best market competition countries were included due to integrated assessment methods in a fuzzy environment. Obtained from annual reports and stock exchange quotations, national deposit sites were structured disclosing their market shares in their countries of establishment.

For this purpose, 2014 end-of-year data were used to calculate market shares. Understanding of market concentration and level of competition is a key point in evaluating possible investment decisions. Having a well-prepared market opportunity analysis, investors could easily decide due to potential market growth. In addition, competition and the level of concentration in the sector could be assessed in detail according to sectoral policies, based on competition principles formation results without some criticism such as homogeneity, market definition [36] so that some regulations could be carried out in order to avoid imperfect market conditions.

Global competition also poses some recent challenges, such as macroeconomics [37], monetary policy, efficiency, transparency, and financial risk. With increasing competition and concentration in the European sector, and various changes in information and communication technologies, the economic and monetary union is causing fierce competition for global industry. That is why it makes sense to compare European competition and concentration.

To this end, the levels of competition and concentration in the European and Slovenian sectors were calculated using an integrated fuzzy decision-making approach. In addition to strategic priorities, a competitive financial system could be restructured considering the multidimensional impact of the growth-based decision-making process on social wellbeing. A set of academics and experts with at least five years of experience was assigned to define the decision-making problem and to model design based on a literature review.

The HHI was used in the specifications of the level of competition and market concentration in the sector. After analyzing the scientific literature, we can state that the DEMATEL method is an appropriate multi-criteria tool assessing the IT sector's sustainability, as it can help to identify which criteria have the greatest impact on a company's HHI index.

\section{Methodology}

The algorithm developed is based on this model and will be tested in a typical area of business-IT services. The developed algorithm is designed to assess IT sector's sustainability, and make strategic decisions. Given the multiplicity of criteria addressed in the sustainability issues, the multi-criteria analysis was used with the assistance of experts.

A typical case is characteristic for the assessment of sustainability-the Slovenian IT sector, the impact of the IT sector on GDP is significant [37]. Knowing the importance of this sector for the Slovenia economy, it is expedient to apply the proposed model to the assessment of the market power of business entities in the Slovenia IT sector. Further, performance indicators of IT sector companies in 2015-2019 are presented. 
The following performance indicators of companies in 2015-2019 were selected for analysis (Table 1):

Table 1. The limits and expressions of indices.

\begin{tabular}{ccc}
\hline No. & Criterion & Units \\
\hline 1 & Turnover from IT sector activities & EUR \\
\hline 2 & Gross operating profit & EUR \\
\hline 3 & Number of hours worked by employees & Hours \\
\hline 4 & Notional number of employees & Persons \\
\hline 5 & Total expenditure on supplies and services & EUR \\
\hline 6 & Revenue from IT sector subcontracting & EUR \\
\hline 7 & Sold tangible fixed assets & EUR \\
\hline 8 & Sales revenue & EUR \\
\hline 9 & Cost of sales & EUR \\
\hline 10 & Operating costs & EUR \\
\hline 11 & Liabilities of companies & EUR \\
\hline 12 & Equity of companies & EUR \\
\hline 13 & Corporate assets & EUR \\
\hline 14 & Debt ratio & - \\
\hline 15 & Businesses entities and markets the HHI index ratio & - \\
\hline
\end{tabular}

To identify the model of the relations among the $\mathrm{n}$ criteria, an $\mathrm{n} \times \mathrm{n}$ matrix is first generated. The effect of the element in each row is exerted on the element of each column of this matrix. If multiple experts' opinions are used, all experts must complete the matrix. An arithmetical mean of all of the experts' opinions is used and then a direct relation matrix $\mathrm{X}$ is generated.

$$
\mathrm{X}=\left[\begin{array}{ccc}
0 & \cdots & x_{n 1} \\
\vdots & \ddots & \vdots \\
x_{1 n} & \cdots & 0
\end{array}\right]
$$

To normalize, the sum of all rows and columns of the matrix is calculated directly. The largest number of the row and column sums can be represented by $k$. To normalize, it is necessary that each element of the direct-relation matrix be divided by $k$.

$$
\begin{gathered}
k=\max \left\{\max \sum_{j=1}^{n} x_{i j}, \sum_{i=1}^{n} x_{i j}\right\} \\
N=\frac{1}{k} * X
\end{gathered}
$$

After calculating the normalized matrix, the fuzzy total-relation matrix can be computed as follows:

$$
T=\lim _{k \rightarrow+\infty}\left(N^{1}+N^{2}+\cdots+N^{k}\right),
$$

In other words, an $\mathrm{n} \times \mathrm{n}$ identity matrix is first generated, then this identity matrix is subtracted from the normalized matrix, and the resulting matrix is reversed. The normalized matrix is multiplied by the resulting matrix to obtain the total relation matrix (Table 2).

$$
\mathrm{T}=N \times(I-N)^{-1},
$$


Table 2. The total relation matrix [37].

\begin{tabular}{|c|c|c|c|c|c|c|c|c|c|c|c|c|c|c|c|}
\hline & Criterion1 & Criterion2 & Criterion3 & Criterion 4 & Criterion5 & Criterion6 & Criterion7 & Criterion8 & Criterion9 & Criterion10 & Criterion11 & Criterion12 & Criterion13 & Criterion14 & Criterion15 \\
\hline criterion1 & 0.21 & 0.28 & 0.24 & 0.25 & 0.24 & 0.28 & 0.26 & 0.14 & 0.28 & 0.25 & 0.19 & 0.19 & 0.26 & 0.23 & 0.09 \\
\hline criterion2 & 0.30 & 0.22 & 0.25 & 0.26 & 0.26 & 0.30 & 0.27 & 0.15 & 0.30 & 0.27 & 0.20 & 0.20 & 0.27 & 0.24 & 0.11 \\
\hline criterion3 & 0.26 & 0.24 & 0.17 & 0.21 & 0.21 & 0.25 & 0.22 & 0.14 & 0.25 & 0.22 & 0.19 & 0.19 & 0.24 & 0.23 & 0.10 \\
\hline criterion4 & 0.26 & 0.26 & 0.21 & 0.17 & 0.25 & 0.26 & 0.23 & 0.13 & 0.26 & 0.23 & 0.18 & 0.17 & 0.24 & 0.21 & 0.09 \\
\hline criterion5 & 0.26 & 0.26 & 0.21 & 0.25 & 0.17 & 0.26 & 0.23 & 0.13 & 0.26 & 0.23 & 0.18 & 0.16 & 0.23 & 0.20 & 0.09 \\
\hline criterion6 & 0.30 & 0.30 & 0.25 & 0.26 & 0.26 & 0.22 & 0.27 & 0.15 & 0.30 & 0.27 & 0.20 & 0.20 & 0.27 & 0.24 & 0.11 \\
\hline criterion7 & 0.28 & 0.27 & 0.23 & 0.23 & 0.23 & 0.27 & 0.18 & 0.13 & 0.26 & 0.24 & 0.18 & 0.17 & 0.23 & 0.21 & 0.09 \\
\hline criterion9 & 0.30 & 0.30 & 0.25 & 0.26 & 0.26 & 0.30 & 0.27 & 0.15 & 0.22 & 0.27 & 0.20 & 0.20 & 0.27 & 0.24 & 0.11 \\
\hline criterion 10 & 0.29 & 0.29 & 0.24 & 0.25 & 0.25 & 0.29 & 0.26 & 0.14 & 0.29 & 0.19 & 0.19 & 0.18 & 0.25 & 0.22 & 0.10 \\
\hline criterion 11 & 0.18 & 0.17 & 0.17 & 0.15 & 0.15 & 0.17 & 0.15 & 0.16 & 0.17 & 0.15 & 0.11 & 0.16 & 0.18 & 0.18 & 0.08 \\
\hline criterion 12 & 0.16 & 0.14 & 0.17 & 0.12 & 0.12 & 0.15 & 0.13 & 0.13 & 0.15 & 0.13 & 0.15 & 0.10 & 0.18 & 0.19 & 0.08 \\
\hline criterion 13 & 0.26 & 0.25 & 0.24 & 0.22 & 0.21 & 0.25 & 0.23 & 0.15 & 0.25 & 0.23 & 0.19 & 0.21 & 0.18 & 0.24 & 0.09 \\
\hline criterion14 & 0.21 & 0.20 & 0.21 & 0.17 & 0.17 & 0.20 & 0.18 & 0.15 & 0.20 & 0.18 & 0.18 & 0.20 & 0.23 & 0.15 & 0.09 \\
\hline criterion15 & 0.30 & 0.29 & 0.28 & 0.26 & 0.26 & 0.29 & 0.28 & 0.22 & 0.29 & 0.27 & 0.26 & 0.26 & 0.29 & 0.29 & 0.09 \\
\hline
\end{tabular}




\section{Results}

The threshold value must be obtained in order to calculate the internal relations matrix. Accordingly, partial relations are neglected and the network relationship map (NRM) is plotted. Only relations whose values in matrix $\mathrm{T}$ is greater than the threshold value are depicted in the NRM. To compute the threshold value for relations, it is sufficient to calculate the average values of the matrix $\mathrm{T}$. After the threshold intensity is determined, all values in matrix $\mathrm{T}$ which are smaller than the threshold value are set to zero, i.e., the causal relation mentioned above is not considered.

In this study, the threshold value is equal to 0.346 .

All the values in matrix $T$ which are smaller than 0.346 are set to zero, meaning that the causal relation mentioned above is not considered. The model of significant relations is presented in the following Table 3.

The sum of rows $(D)$ and columns $(R)$ can be calculated as follows:

$$
\begin{aligned}
& D=\sum_{j=1}^{n} T_{i j} \\
& R=\sum_{i=1}^{n} T_{i j},
\end{aligned}
$$

Then, the values of $D+R$ and $D-R$ can be calculated by $D$ and $R$, where $D+R$ represent the degree of importance of factor $i$ in the entire system and $D-R$ represent net effects that factor $i$ contributes to the system.

Table 4 below shows the final output.

The following Figure 2 shows the model of significant relations. This model can be represented as a diagram in which the values of $(D+R)$ are placed on the horizontal axis and the values of $(D-R)$ on the vertical axis. The position and interaction of each factor with a point in the coordinates $(D+R, D-R)$ are determined by a coordinate system.

According to the diagram and table above, each factor can be assessed based on the following aspects:

- Horizontal vector $(D+R)$ represents the degree of importance between each factor playing in the entire system. In other words, $(D+R)$ indicates both factor i's impact on the whole system and other system factors' impact on the factor in terms of degree of importance, criterion9 is ranked in first place and criterion6, criterion2, criterion1, criterion10, criterion13, criterion7, criterion3, criterion4, criterion5, criterion14, criterion15, criterion11, criterion12, and criterion8 are ranked in the next places.

- The vertical vector $(D-R)$ represents the degree of a factor's influence on the system. In general, the positive value of $D-R$ represents a causal variable, and the negative value of $D-R$ represents an effect. In this study, criterion2, criterion10, and criterion15 are considered to be as a causal variables; criterion1, criterion3, criterion4, criterion5, criterion6, criterion7, criterion8, criterion9, criterion11, criterion12, criterion13, and criterion14 are regarded as an effect. 
Table 3. The total-relationships matrix by considering the threshold value.

\begin{tabular}{|c|c|c|c|c|c|c|c|c|c|c|c|c|c|c|c|}
\hline & Criterion1 & Criterion2 & Criterion 3 & Criterion4 & Criterion5 & Criterion6 & Criterion7 & Criterion8 & Criterion9 & Criterion10 & Criterion11 & Criterion12 & Criterion13 & Criterion14 & Criterion15 \\
\hline criterion1 & 0.21 & 0.28 & 0.24 & 0.25 & 0.24 & 0.28 & 0.26 & 0.00 & 0.28 & 0.25 & 0.00 & 0.00 & 0.26 & 0.23 & 0.00 \\
\hline criterion2 & 0.30 & 0.22 & 0.25 & 0.26 & 0.26 & 0.30 & 0.27 & 0.00 & 0.30 & 0.27 & 0.00 & 0.00 & 0.27 & 0.24 & 0.00 \\
\hline criterion3 & 0.26 & 0.24 & 0.00 & 0.21 & 0.21 & 0.25 & 0.22 & 0.00 & 0.25 & 0.22 & 0.00 & 0.00 & 0.24 & 0.23 & 0.00 \\
\hline criterion4 & 0.26 & 0.26 & 0.21 & 0.00 & 0.25 & 0.26 & 0.23 & 0.00 & 0.26 & 0.23 & 0.00 & 0.00 & 0.24 & 0.21 & 0.00 \\
\hline criterion5 & 0.26 & 0.26 & 0.21 & 0.25 & 0.00 & 0.26 & 0.23 & 0.00 & 0.26 & 0.23 & 0.00 & 0.00 & 0.23 & 0.00 & 0.00 \\
\hline criterion6 & 0.30 & 0.30 & 0.25 & 0.26 & 0.26 & 0.22 & 0.27 & 0.00 & 0.30 & 0.27 & 0.00 & 0.00 & 0.27 & 0.24 & 0.00 \\
\hline criterion7 & 0.28 & 0.27 & 0.23 & 0.23 & 0.23 & 0.27 & 0.00 & 0.00 & 0.26 & 0.24 & 0.00 & 0.00 & 0.23 & 0.21 & 0.00 \\
\hline criterion9 & 0.30 & 0.30 & 0.25 & 0.26 & 0.26 & 0.30 & 0.27 & 0.00 & 0.22 & 0.27 & 0.00 & 0.00 & 0.27 & 0.24 & 0.00 \\
\hline criterion10 & 0.29 & 0.29 & 0.24 & 0.25 & 0.25 & 0.29 & 0.26 & 0.00 & 0.29 & 0.00 & 0.00 & 0.00 & 0.25 & 0.22 & 0.00 \\
\hline criterion11 & 0.00 & 0.00 & 0.00 & 0.00 & 0.00 & 0.00 & 0.00 & 0.00 & 0.00 & 0.00 & 0.00 & 0.00 & 0.00 & 0.00 & 0.00 \\
\hline criterion12 & 0.00 & 0.00 & 0.00 & 0.00 & 0.00 & 0.00 & 0.00 & 0.00 & 0.00 & 0.00 & 0.00 & 0.00 & 0.00 & 0.00 & 0.00 \\
\hline criterion13 & 0.26 & 0.25 & 0.24 & 0.22 & 0.21 & 0.25 & 0.23 & 0.00 & 0.25 & 0.23 & 0.00 & 0.21 & 0.00 & 0.24 & 0.00 \\
\hline criterion14 & 0.21 & 0.00 & 0.21 & 0.00 & 0.00 & 0.00 & 0.00 & 0.00 & 0.00 & 0.00 & 0.00 & 0.00 & 0.23 & 0.00 & 0.00 \\
\hline criterion15 & 0.30 & 0.29 & 0.28 & 0.26 & 0.26 & 0.29 & 0.28 & 0.22 & 0.29 & 0.27 & 0.26 & 0.26 & 0.29 & 0.29 & 0.00 \\
\hline
\end{tabular}


Table 4. The final output.

\begin{tabular}{ccccc}
\hline & $\boldsymbol{R}$ & $\boldsymbol{D}$ & $\boldsymbol{D}+\boldsymbol{R}$ & $\boldsymbol{D}-\boldsymbol{R}$ \\
\hline criterion1 & 3.721 & 3.401 & 7.122 & -0.32 \\
\hline criterion2 & 3.58 & 3.598 & 7.178 & 0.018 \\
\hline criterion3 & 3.222 & 3.12 & 6.342 & -0.101 \\
\hline criterion4 & 3.153 & 3.14 & 6.293 & -0.013 \\
\hline criterion5 & 3.122 & 3.117 & 6.239 & -0.004 \\
\hline criterion6 & 3.616 & 3.567 & 7.183 & -0.049 \\
\hline criterion7 & 3.274 & 3.192 & 6.466 & -0.082 \\
\hline criterion8 & 2.104 & 1.708 & 3.812 & -0.396 \\
\hline criterion9 & 3.596 & 3.595 & 7.191 & -0.001 \\
\hline criterion10 & 3.241 & 3.412 & 6.654 & 0.171 \\
\hline criterion11 & 2.71 & 2.305 & 5.016 & -0.405 \\
\hline criterion12 & 2.701 & 2.094 & 4.794 & -0.607 \\
\hline criterion13 & 3.449 & 3.188 & 6.636 & -0.261 \\
criterion14 & 3.196 & 2.708 & 5.904 & -0.488 \\
\hline criterion15 & 1.397 & 3.935 & 5.333 & 2.538 \\
\hline
\end{tabular}

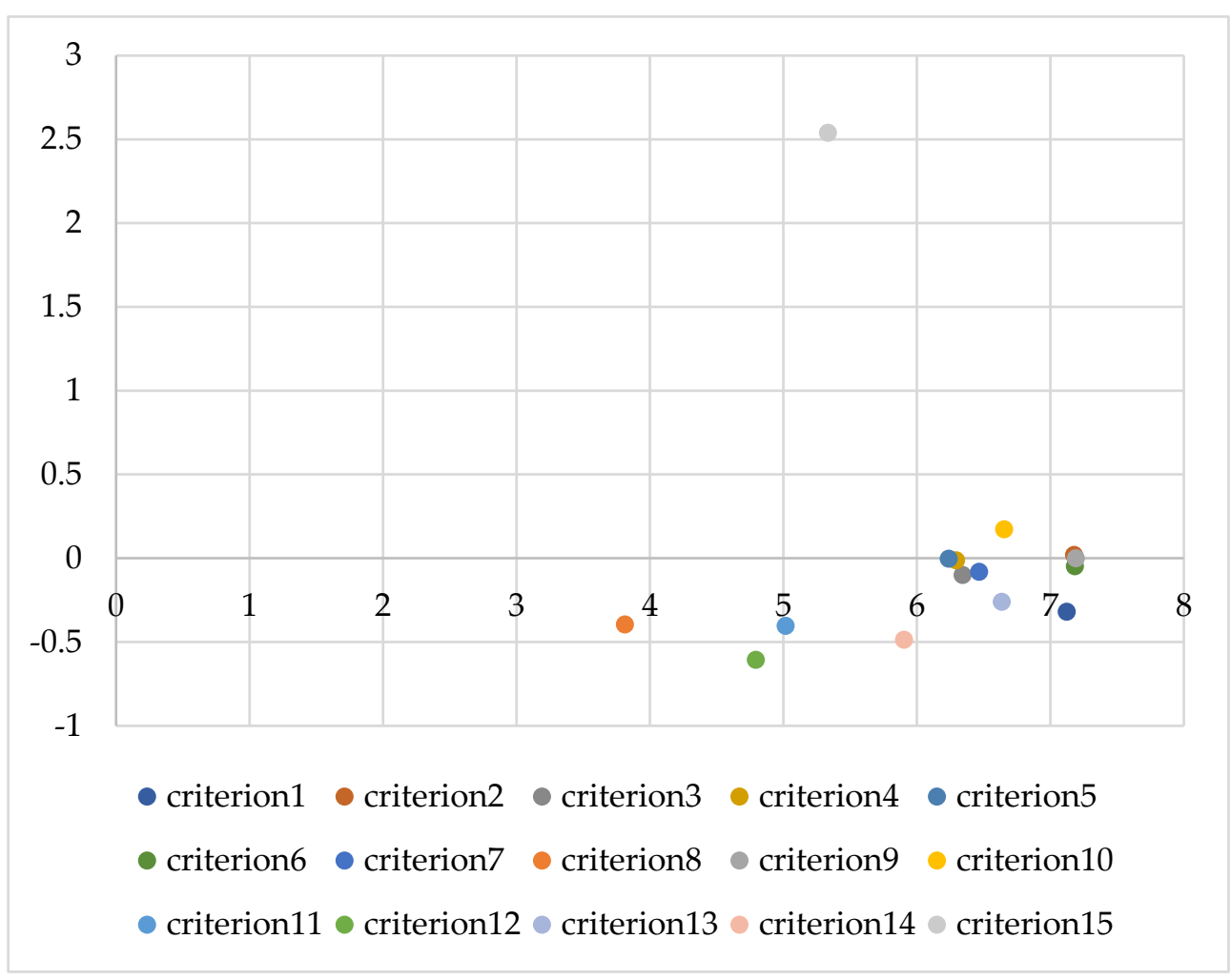

Figure 2. Cause-effect diagram.

\section{Discussion}

The DEMATEL method identifies net causes and net consequences, forms an interrelationship map (IRM) between factors based on a threshold value, and finally presents the structure of the system. Combining a cognitive map with fuzzy logic creates a fuzzy cognitive map, which depicts the presented system graphically. Bayesian networks also generate graphical models that reflect information related to an undecided domain. ISM is 
used to determine factor relationships and clearly define problems. "System dynamics" defines problems that dynamically present different phases of modeling and mapping and helps to understand multiple problems, and SEM also defines a structural relationship of factors to present statistical results. All these methods have certain strengths and weaknesses, but the DEMATEL methodology is more popular for the following reasons: it is relatively less inflexible.

Compared to the fuzzy set and probability theories, the main advantage of the DEMATEL method is the lower data volume requirement and greater flexibility in pattern recognition. Another major advantage of DEMATEL over other systems is its confidence in the ability to achieve possible results using the least amount of data. The matrix portrait depicts contextual associations between system elements, where numbers reflect the strength of influences. Most decision-making methods assume that there is independence between the decision criteria and alternatives to that solution, or simply between the criteria or alternatives themselves. However, the assumption that the criteria/variables are independent is too strict to overcome the problem of dependent criteria. Therefore, some articles discuss ways to overcome this problem.

In this article, the IT sector's Operating costs, Businesses entities and markets, and the $\mathrm{HHI}$ index ratio are used as a causal variables. Turnover, Gross operating profit, Number of hours worked by employees, Notional number of employees, Total expenditure on supplies and services, Revenue from subcontracting, Sold tangible fixed assets, Sales revenue, Cost of sales, Liabilities of companies, Equity of companies, corporate assets, and Debt ratio are regarded as an effect.

Further research should extend the remaining concentration indices to assess the competitive situation in the IT sector using the DEMATEL method. The applicability of these methods to different levels of distorted market should also be assessed.

\section{Conclusions}

(1) The DEMATEL method works mainly by gathering expert's opinions, monitoring the degree of influence between elements, using matrix operations to obtain a causal relationship between elements, and identifying similar network schemes for modeling structural equations. Comparison of the DEMATEL method with fuzzy and probability theories proved that, by using an integrated fuzzy decision-making approach, it is possible to measure the IT sector's HHI-based performance. Research limitations: IT sectors sustainability assessments are based on the empirical evidence available for the application and verification of the IT sector's market players' performance.

(2) Developing the modified DEMATEL technique for problem solving: The purpose of DEMATEL is to convert causal relationships between elements of a complex system into an understandable structural model. DEMATEL helps to draw a structure of complex causal relationships between evaluation criteria using matrices or graphs. Assessing the concentration of business entities that affect the competitive situation in economics, the DEMATEL method is an appropriate multi-criteria tool estimating the IT sector's sustainability as it can help to identify which criteria have the greatest impact on a company's HHI index.

(3) In empirical part, the model was applied and tested, which is intended to assist in the preparation of IT sector's business strategies based on assessments of the IT sector's sustainability. The algorithm developed based on this model was tested in a typical area of business-IT services. The developed algorithm was designed to assess the IT sector's sustainability, to analyse strategic actions, and make strategic decisions. Given the multiplicity of criteria addressed in the sustainability issues, multi-criteria analysis was used with the assistance of experts.

(4) In the empirical results diagram, the vertical vector Horizontal vector ( $D+R)$ represented the degree of importance that each factor has in the entire system. In other words, $(D+R)$ indicated both factor i's impact on the whole system and other system factors' impact on the factor in terms of degree of importance; criterion9 was ranked 
in first place and criterion6, criterion2, criterion1, criterion10, criterion13, criterion7, criterion3, criterion4, criterion5, criterion14, criterion15, criterion11, criterion12, and criterion8 were ranked in the next places. In the results diagram, the vertical vector $(\mathrm{D}-\mathrm{R})$ represented the degree of a factor's influence on the system. In general, the positive value of $D-R$ represented a causal variable, and the negative value of $\mathrm{D}-\mathrm{R}$ represented an effect. In this study, criterion2, criterion10, and criterion15 were considered to be as a causal variable, and criterion1, criterion3, criterion4, criterion5, criterion6, criterion7, criterion8, criterion9, criterion11, criterion12, criterion13, and criterion14 were regarded as an effect.

Funding: This project has received funding from European Social Fund (project No 09.3.3-LMT-K712-19-0025) under grant agreement with the Research Council of Lithuania (LMTLT).

Institutional Review Board Statement: Not applicable.

Informed Consent Statement: Not applicable.

Data Availability Statement: Not applicable.

Conflicts of Interest: The authors declare no conflict of interest.

\section{References}

1. Schøne, P.; Strøm, M. International labor market competition and wives' labor supply responses. Labour Econ. 2021, 70. [CrossRef]

2. Huang, Y.; Qian, L. Buy, lease, or share? Consumer preferences for innovative business models in the market for electric vehicles. Technol. Forecast. Soc. Chang. 2021, 166, 120639. [CrossRef]

3. Fernández-Villaverde, J.; Mandelman, F.; Yu, Y.; Zanetti, F. The "Matthew effect" and market concentration: Search complementarities and monopsony power. J. Monetary Econ. 2021, 121, 62-90. [CrossRef]

4. Hirche, M.; Farris, P.; Greenacre, L.; Quan, Y.; Wei, S. Predicting Under- and Overperforming SKUs within the Distribution-Market Share Relationship. J. Retail. 2021, 97. [CrossRef]

5. Guissoni, L.; Rodrigues, J.; Zambaldi, F. Distribution effectiveness through full- and self-service channels under economic fluctuations in an emerging market. J. Retail. 2021. [CrossRef]

6. Wang, J.; Wu, C.; Zhong, X. Prospect theory and stock returns: Evidence from foreign share markets. Pac.-Basin Financ. J. 2021, 101644. [CrossRef]

7. Panzar, J.C.; James, N.R. Testing for Monopoly Equilibrium. J. Ind. Econ. 1987, 4, 443-456. [CrossRef]

8. Prayoonrattana, J.; Laosuthi, T.; Chaivichayachat, B. Empirical Measurement of Competition in the Thai Banking Industry. Economies 2020, 8, 44. [CrossRef]

9. Subramaniam, R.; Prakash, V.; Ab-Rahim, R.; Selvarajan, S.K. Financial Development, Eciency, and Competition of ASEAN Banking Market. Asia-Pac. Soc. Sci. Rev. 2019, 19, 185-202.

10. Dobrovolskienè, N.; Pozniak, A.; Tvaronavičienè, M. Assessment of the sustainability of a real estate project using multi-criteria decision making. Sustainability 2021, 13, 4352. [CrossRef]

11. Dobrovolskienè, N.; Tvaronavičienè, M.; Jurènaitė, K. Selection of a transport investment project based on sustainability index, return on investment and risk. Arct. J. 2021, 74, 117-140.

12. Stigler, G.J. A Theory of Oligopoly. J. Polit. Econ. 1964, 72, 44-61. [CrossRef]

13. Jenkins, M.; Liu, P. The browser war-Analysis of Markov Perfect Equilibrium in markets with dynamic demand effects. J. Econom. 2021, 222, 244-260. [CrossRef]

14. Brooks, W.; Kaboski, J. Exploitation of labor? Classical monopsony power and labor's share. J. Dev. Econ. 2021, 150, 102627. [CrossRef]

15. Chortareas, G.; Noikokyris, E. Investment, firm-specific uncertainty, and market power in South Africa. Econ. Model. 2021, 96, 389-395. [CrossRef]

16. Tvaronavičienė, M. If industrial sector development is sustainable: Lithuania compared to the EU. Entrep. Sustain. Issues 2014, 1, 134-142. [CrossRef]

17. Marcysiak, A.; Pleskacz, Ż. Determinants of digitization in SMEs. Entrep. Sustain. Issues 2021, 9, 300-318. [CrossRef]

18. Shevyakova, A.; Arystan, M.; Petrenko, Y. Competence development for Industry 4.0: Qualification requirements and solutions. Insights Into Reg. Dev. 2021, 3, 124-135. [CrossRef]

19. Meidutè-Kavaliauskienè, I.; Davidavičienè, V.; Karakaya, G.; Shahryar, G. The measurement of organizational social media integration impact on financial and innovative performance: An integrated model. Sustainability 2021, 13, 10397. [CrossRef]

20. Qiao, S.; Shen, T.; Zhang, R.R.; Chen, H.H. The impact of various factor market distortions and innovation efficiencies on profit sustainable growth: From the view of China's renewable energy industry. Energy Strategy Rev. 2021, 38, 100746. [CrossRef]

21. ICT Sector, Digital Economy and Society. 2021. Available online: https://appsso.eurostat.ec.europa.eu/nui/show.do?dataset= isoc_ec_eseln2\&lang=en (accessed on 14 October 2021). 
22. Gyimah, D.; Siganos, A.; Veld, C. Effects of financial constraints and product market competition on share repurchases, Journal of International Financial Markets. Inst. Money 2021, 74, 101392. [CrossRef]

23. Mao, Z.; Duan, Y.; Yao, Y.; Huo, J. The moderating effect of average wage and number of stores on private label market share: A hierarchical linear model analysis. J. Retail. Consum. Serv. 2021, 60, 102454. [CrossRef]

24. Mukherjee, A.; Carvalho, M. Dynamic decision making in a mixed market under cooperation: Towards sustainability. Int. J. Prod. Econ. 2021, 241, 108270. [CrossRef]

25. Lee, C.; Rhee, B. Retailer-run resale market and supply chain coordination. Int. J. Prod. Econ. 2021, 235, 108089. [CrossRef]

26. Amir, R.; Machowska, D.; Troege, M. Advertising patterns in a dynamic oligopolistic growing market with decay. J. Econ. Dynam. Control 2021, 104229. [CrossRef]

27. Liou, J.J.H.; Tzeng, G.H. Comments on "multiple criteria decision making (mcdm) Methods in economics: An overview". Technol. Econ. Dev. Econ. 2012, 18, 672-695. [CrossRef]

28. Tzeng, G.H.; Huang, J.J. Multiple Attribute Decision Making: Methods and Applications; CRC Press: Boca Raton, FL, USA, 2011.

29. Hwang, C.L.; Yoon, K. Multiple Attribute Decision Making-Methods and Applications: A State of the Art Survey; Springer: New York, NY, USA, 1981.

30. Koksalan, M.; Wallenius, J.; Zionts, S. Multiple Criteria Decision Making: From Early History to the 21st Century; World Scientific: Singapore; John Wiley \& Sons, Ltd.: Hoboken, NJ, USA, 2011; 212p.

31. Sivakumar, R. Methods and Resources in Teaching Social Studies. 2018. Available online: https://www.researchgate.net/ publication/326356212_METHODS_AND_RESOURCES_IN_TEACHING_SOCIAL_STUDIES (accessed on 12 September 2021).

32. Chen, Y.; Wei, X.; Zhang, L.; Shi, Y. Sectoral diversification and the banks' return and risk: Evidence from Chinese listed commercial banks. Procedia Comp. Sci. 2013, 18, 1737-1746. [CrossRef]

33. Alegria, C.; Schaeck, K. On measuring concentration in banking systems. Financ. Res. Lett. 2008, 5, 59-67. [CrossRef]

34. Diallo, B. Bank competition and crises revisited: New results. Econ. Lett. 2015, 129, 81-86. [CrossRef]

35. Nickell, S. Competition and Corporate Performance. J. Polit. Econ. 1996, 104, 724-746. [CrossRef]

36. Oliveira, A.V.; Lohmann, G.; Costa, T.G. Network concentration and airport congestion in a post de-regulation context: Case study of Brazil 2000-2010. J. Transp. Geogr. 2016, 50, 33-44. [CrossRef]

37. Olivero, M.P.; Yuan, L.; Bang, N.J. Competition in banking and lending channel: Evidence from bank-Level data in Asia and Latin America. J. Bank. Financ. 2011, 35, 560-571. [CrossRef] 